\title{
Selective laser trabeculoplasty in primary open-angle glaucoma: Primary versus secondary treatment outcomes
}

\begin{tabular}{|c|c|}
\hline \multicolumn{2}{|c|}{$\begin{array}{l}\text { Authors: } \\
\text { Emil Goosen }^{1} \\
\text { Linda Visser }^{1} \\
\text { Ben Sartorius }\end{array}$} \\
\hline \multicolumn{2}{|c|}{$\begin{array}{l}\text { Affiliations: } \\
{ }^{1} \text { Department of } \\
\text { Ophthalmology, University of } \\
\text { KwaZulu-Natal, South Africa }\end{array}$} \\
\hline \multicolumn{2}{|c|}{$\begin{array}{l}{ }^{2} \text { Department of Public Health } \\
\text { Medicine, University of } \\
\text { KwaZulu-Natal, South Africa }\end{array}$} \\
\hline \multicolumn{2}{|c|}{$\begin{array}{l}\text { Corresponding author: } \\
\text { Emil Goosen, } \\
\text { goosenemil@gmail.com }\end{array}$} \\
\hline \multicolumn{2}{|c|}{$\begin{array}{l}\text { Dates: } \\
\text { Received: } 05 \text { Dec. } 2015 \\
\text { Accepted: } 21 \text { Apr. } 2016 \\
\text { Published: } 03 \text { Nov. } 2016\end{array}$} \\
\hline \multicolumn{2}{|c|}{$\begin{array}{l}\text { How to cite this article: } \\
\text { Goosen E, Visser L, Sartorius } \\
\text { B. Selective laser } \\
\text { trabeculoplasty in primary } \\
\text { open-angle glaucoma: } \\
\text { Primary versus secondary } \\
\text { treatment outcomes. Afr } \\
\text { Vision Eye Health. } \\
\text { 2016;75(1), a338. http:// } \\
\text { dx.doi.org/10.4102/aveh. } \\
\text { v75i1.338 }\end{array}$} \\
\hline \multicolumn{2}{|c|}{$\begin{array}{l}\text { Copyright: } \\
\text { (C) 2016. The Author( } \\
\text { Licensee: AOSIS. This } \\
\text { is licensed under the } \\
\text { Creative Commons } \\
\text { Attribution License. }\end{array}$} \\
\hline \multicolumn{2}{|l|}{ Read online: } \\
\hline 回歺回 & $\begin{array}{l}\text { Scan this QR } \\
\text { code with your } \\
\text { smart phone or } \\
\text { mobile device } \\
\text { to read online. }\end{array}$ \\
\hline
\end{tabular}

Objective: To compare the outcomes of selective laser trabeculoplasty (SLT) on treatmentnaive, primary open-angle glaucoma (POAG) patients with those of SLT on patients previously treated medically and/or surgically. Secondary objectives: To establish whether age, race or gender influenced SLT outcomes.

Design: A retrospective chart review of patients who received SLT therapy for POAG between June 2011 and January 2015.

Subjects: Group A: Treatment-naive patients $(n=15)$. Group B: Prior medical therapy and/or prior surgery $(n=69)$.

Methods: Group A: Patients were treated with SLT therapy as first line, with medical treatment added as needed. Group B: Patients were treated with SLT therapy as additional therapy to medication and/or surgery. All patients were followed up for at least 1 year.

Main outcome measures: A reduction in intraocular pressure (IOP) of at least $20 \%$ from baseline was considered significant.

Results: The following percentage reduction in IOP was found in the different groups: Group A 50.7\%, Group B 32.0\%, Africans 52.2\%, Indians 29.8\% and Caucasians 28.87\%.

Conclusion: In our study patients, SLT achieved significant reductions in IOPs in treatmentnaive as well as previously surgically and medically treated eyes with POAG. Statistically significant higher reductions in IOP at 1 year after SLT was seen in treatment-naive eyes, patients older than 70 years when compared with younger patients, female patients (54\%) when compared with male patients (30\%) and in patients of African (52\%) descent compared with Caucasians (30\%).

\section{Introduction}

There is no simple answer to how to treat primary open-angle glaucoma (POAG). To date, the only proven modality to slow down the disease progression is to lower the intraocular pressure (IOP). Various treatment options exist, ranging from medication to laser treatments and surgical intervention.

This study was conducted to determine if there is a difference in the outcomes of selective laser trabeculoplasty (SLT) therapy in treatment-naive POAG patients compared with those who have had prior medical or surgical therapy. The study also looked at the possible influence of age, ethnicity and gender on the outcomes of SLT. Could SLT therapy be considered a first-line therapy for $\mathrm{POAG}^{1,2,3,4}$ or should its main role be as a supportive treatment to medical and surgical therapy? What is the survival time of SLT treatment? ${ }^{5,6}$

In order to stop progression of glaucomatous nerve fibre loss, a target IOP should be set before commencing treatment. ${ }^{1,7}$ This is generally accepted as a reduction in IOP of $20 \%$ from baseline. This figure is only a guideline. The target IOP should be tailored to each patient according to merit and should be adjusted if progression still occurs despite reaching the previous target IOP.

The European Glaucoma Society (EGS) has shown that first-line SLT is effective in $85 \%$ of cases. They reported a drop in IOP of $6 \mathrm{mmHg}-9 \mathrm{mmHg} .{ }^{1}$ The effect was also shown to last 5 years in $50 \%-60 \%$ of patients. ${ }^{3}$ 
Previous cataract surgery does seem to reduce the effect of primary SLT therapy, with a reduced drop in IOP, but levels are comparable in the long term. ${ }^{8}$

SLT has proven its safety and repeatability as seen in the EGS guidelines, ${ }^{1}$ building on the research done by the Glaucoma Laser Trial ${ }^{9}$ that looked at argon laser trabeculoplasty (ALT). ALT cannot be safely repeated as it causes local destruction of tissue, whereas SLT causes remodelling of the trabecular meshwork. ${ }^{10}$

\section{Research methods and design}

The study was conducted as a retrospective chart review of patients who received SLT therapy for POAG over a 5-year period, spanning from 2011 to 2015, at St Aidan's Regional Mission Hospital, Durban, South Africa.

\section{Aims}

In this study, we set out to prove the IOP-lowering effect of SLT in South African patients with POAG of the eye. By doing so, we could potentially reduce the need for medical and surgical intervention. Could SLT become the standard primary treatment in POAG?

\section{Specific objectives}

The objectives are:

- To determine the outcome of SLT on treatment-naive POAG patients (Group A).

- To determine the outcome of SLT on POAG patients previously receiving topical and/or systemic IOP-lowering agents and/or previously operated upon (Group B).

- To determine, using multiple regression analysis, if SLT outcomes are influenced by ethnicity, gender, age or previous glaucoma treatment.

IOP, medication and surgical interventions were noted at 1, 3, 6 and 12 months after SLT therapy.

Informed consent was not obtained from patients included in this study, as it was a retrospective chart review. Institutional Review Board and Ethics committee approval was obtained from the University of KwaZulu-Natal Biomedical Research Ethics Committee. The described research adhered to the Declaration of Helsinki.

Data were entered into SPSS version 21 (Statistical Packages for the Social Sciences) for analysis. Statistical significance was considered as $p<0.05$. A descriptive statistical analysis of the data (means, standard deviations, ranges, frequencies and percentages) was conducted before inferential statistics were done. A one-sample $t$-test was used to assess the differences in IOP. Multiple regression analyses were used to ascertain if race, age, gender or previous glaucoma treatment were indicators of glaucoma outcomes. Eighty-four patients (148 eyes) were enrolled in the trial (see Tables 1 and 2 for patient demographic details).
TABLE 1: Age and gender distribution.

\begin{tabular}{|c|c|c|c|}
\hline \multirow[t]{2}{*}{ Age group } & \multicolumn{2}{|c|}{ Gender } & \multirow[t]{2}{*}{ Total } \\
\hline & Male & Female & \\
\hline $30-39$ & 5 & 1 & 6 \\
\hline $40-49$ & 4 & 7 & 11 \\
\hline 50-59 & 13 & 13 & 26 \\
\hline $60-69$ & 13 & 9 & 22 \\
\hline $70-79$ & 6 & 11 & 17 \\
\hline 80-89 & 0 & 2 & 2 \\
\hline Total & 41 & 43 & 84 \\
\hline
\end{tabular}

TABLE 2: Ethnic make-up of study sample.

\begin{tabular}{lcc}
\hline Patient demographic & Group A & Group B \\
\hline African & 11 & 49 \\
Indian & 4 & 17 \\
Caucasian & 0 & 3 \\
Male & 6 & 35 \\
Female & 9 & 34 \\
\hline
\end{tabular}

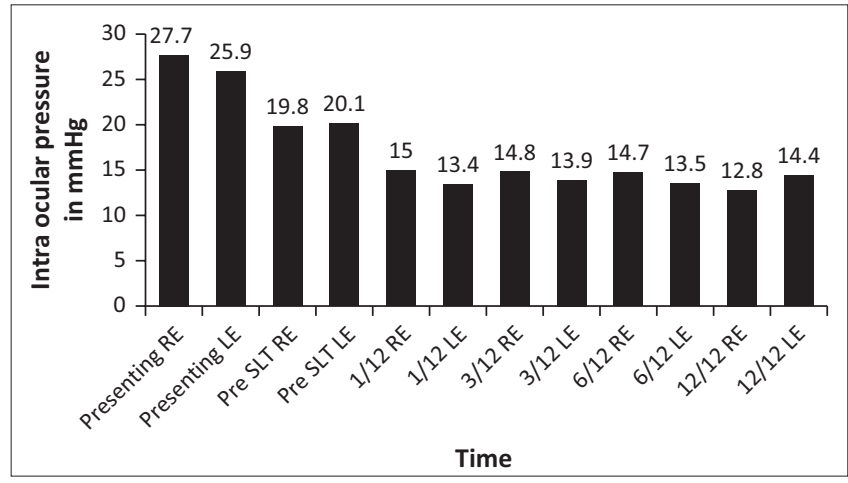

RE, Right eye; LE, Left eye; SLT, selective laser trabeculoplasty.

FIGURE 1: Combined chart of mean intraocular pressure over 1 year.

\section{Results}

A total of 148 eyes of 84 patients were evaluated. Group A consisted of 29 eyes, while Group B had 119 eyes. A greater than $20 \%$ reduction in IOP was achieved in $71 \%$ of eyes at month $1,79 \%$ at month $3,76 \%$ at month 6 and $81 \%$ at 1 year.

The mean pre SLT IOP was $19.95 \mathrm{mmHg}$, reducing to a mean IOP at 1 month of $14.2 \mathrm{mmHg}$ (29\% reduction), $14.35 \mathrm{mmHg}$ at 3 months (33\% reduction), $14.1 \mathrm{mmHg}$ at 6 months (29\% reduction) and $13.6 \mathrm{mmHg}$ at 1 year (32\% reduction). This result compares favourably to a reduction of $24.3 \%$ at 1 year, found by Weinand et al. ${ }^{5}$

The mean reduction in IOP exceeded the required $20 \%$ stipulated in the study protocol (Figure 1).

In Group A, the mean pre SLT IOP was $27.07 \mathrm{mmHg}$; it was $16.76 \mathrm{mmHg}$ at 1 month after SLT, $16.09 \mathrm{mmHg}$ at 3 months, $14.72 \mathrm{mmHg}$ at 6 months and $13.33 \mathrm{mmHg}$ at 1 year. There was a $51 \%$ reduction in mean IOP from the baseline value.

The percentage of patients who reduced their IOP by more than $20 \%$ was $68 \%$ at 1 month, $91 \%$ at 3 months, $89 \%$ at 6 months and $95 \%$ at 1 year (see Table 3 and Figure 2). There was a significantly reduced need for medical therapy in 
TABLE 3: Mean intraocular pressure drop Group A versus Group B.

\begin{tabular}{|c|c|c|c|c|}
\hline Group $(p<0.001)$ & Time & Mean IOP (mmHg) & Mean IOP reduction & Reduction from baseline (\%) \\
\hline \multirow[t]{5}{*}{ Group A } & Pre SLT & 27.07 & - & - \\
\hline & $1 / 12$ post SLT & 16.76 & -10.31 & 38.1 \\
\hline & $3 / 12$ post SLT & 16.09 & -10.98 & 40.6 \\
\hline & $6 / 12$ post SLT & 14.72 & -12.35 & 45.6 \\
\hline & $12 / 12$ post SLT & 13.33 & -13.74 & 50.7 \\
\hline \multirow[t]{5}{*}{ Group B } & Pre SLT therapy & 18.97 & - & - \\
\hline & $1 / 12$ post SLT & 13.70 & -5.27 & - \\
\hline & $3 / 12$ post SLT & 14.45 & -4.52 & 27.8 \\
\hline & $6 / 12$ post SLT & 14.50 & -4.47 & 23.8 \\
\hline & $12 / 12$ post SLT & 12.90 & -6.07 & 23.5 \\
\hline
\end{tabular}

IOP, Intraocular pressure; SLT, Selective laser trabeculoplasty.

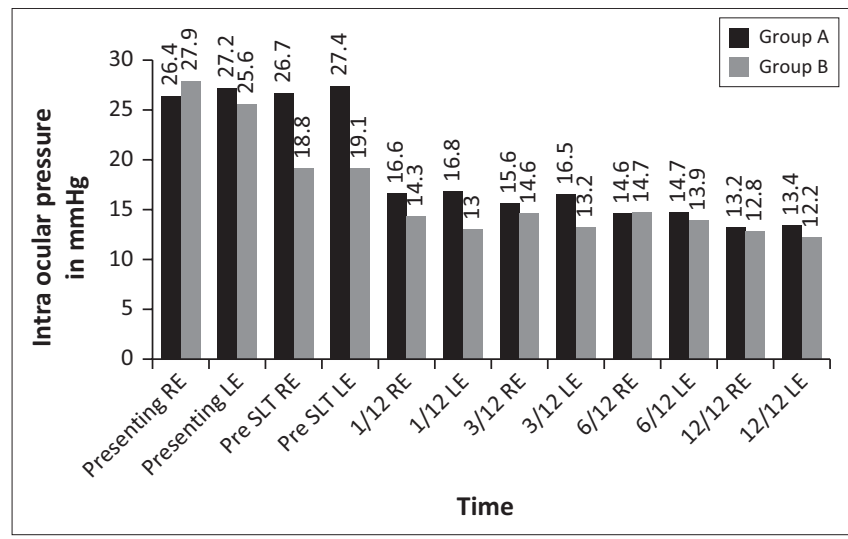

RE, Right eye; LE, Left eye; SLT, selective laser trabeculoplasty.

FIGURE 2: Mean intraocular pressure in Group A versus Group B.

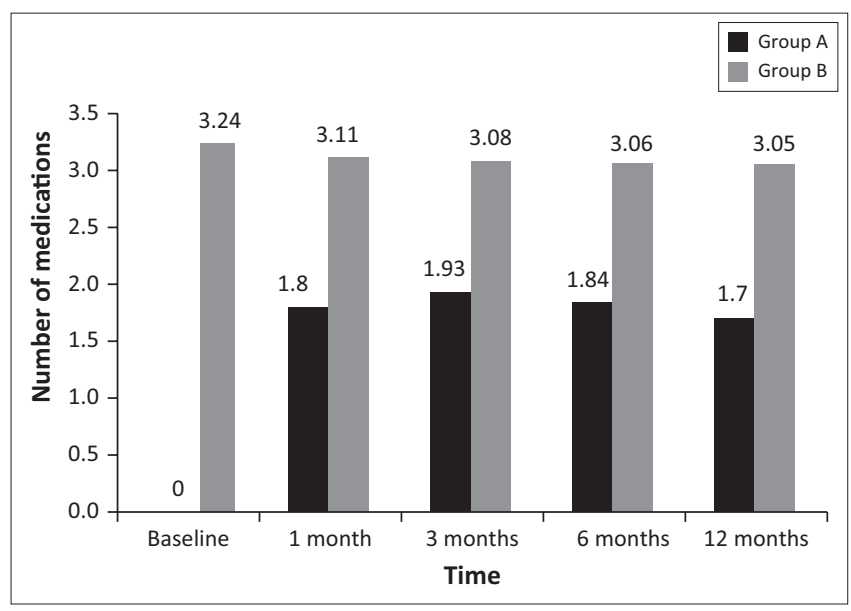

FIGURE 3: Number of medications needed after selective laser trabeculoplasty.

Group A versus Group B, highlighting the effect and sustainability of SLT (see Figure 3).

In Group B, the mean pre SLT IOP was $18.97 \mathrm{mmHg}$; it was $13.70 \mathrm{mmHg}$ at 1 month, $14.45 \mathrm{mmHg}$ at 3 months, $14.5 \mathrm{mmHg}$ at 6 months and $12.9 \mathrm{mmHg}$ at 1 year. There was a reduction in mean IOP of $32 \%$ at 1 year.

The percentage of patients who reduced their IOP by more than $20 \%$ was $72 \%$ at 1 month, $75 \%$ at 3 months, $70 \%$ at 6 months and $77 \%$ at 1 year.

There was a $15 \%$ reduction in the use of acetazolamide. This enforces the need for SLT as a first-line therapy to reduce
TABLE 4: Additional therapy needed after selective laser trabeculoplasty in Group A versus Group B.

\begin{tabular}{|c|c|c|c|}
\hline Month & Medication & Group A (\%) & Group B (\%) \\
\hline \multirow[t]{6}{*}{1 Month } & Prostaglandin & 53 & 89 \\
\hline & Beta blocker & 53 & 97 \\
\hline & Alpha agonist & 46 & 82 \\
\hline & Pilocarpine & - & 1 \\
\hline & Acetazolamide & 26 & 40 \\
\hline & Repeat SLT & - & 1 \\
\hline \multirow[t]{6}{*}{3 Months } & Prostaglandin & 60 & 89 \\
\hline & Beta blocker & 53 & 97 \\
\hline & Alpha agonist & 53 & 82 \\
\hline & Pilocarpine & - & 1 \\
\hline & Acetazolamide & 26 & 38 \\
\hline & Repeat SLT & - & 1 \\
\hline \multirow[t]{6}{*}{6 Months } & Prostaglandin & 53 & 89 \\
\hline & Beta blocker & 53 & 95 \\
\hline & Alpha agonist & 44 & 80 \\
\hline & Pilocarpine & - & 1 \\
\hline & Acetazolamide & 15 & 39 \\
\hline & Repeat SLT & - & 3 \\
\hline \multirow[t]{6}{*}{12 Months } & Prostaglandin & 50 & 89 \\
\hline & Beta blocker & 50 & 92 \\
\hline & Alpha agonist & 50 & 82 \\
\hline & Pilocarpine & - & 1 \\
\hline & Acetazolamide & 20 & 39 \\
\hline & Repeat SLT & 10 & 1 \\
\hline
\end{tabular}

SLT, selective laser trabeculoplasty.

the use of medication, as Group A required far fewer medications (Table 4).

Analysing the differences in gender, $82 \%$ of the male patients $(n=41)$ had a reduction in IOP of at least $20 \%$ at 1 year compared with $77 \%$ of female patients $(n=43)$. Male patients had a $30 \%$ reduction in mean IOP from baseline at 1 year compared with a $54 \%$ reduction in female patients. This large difference in IOP reduction cannot be fully explained, but is significant. A follow-up trial of a prospective controlled design would be useful to further study these results (see Table 5).

Analysing the different ethnic groups, we found a reduction of IOP of at least $20 \%$ at 1 year in $90 \%$ of African patients compared with $54 \%$ in the Indian subgroup and $83 \%$ in the Caucasian subgroup. This supports the theory that SLT directly targets melanocytes in the trabecular meshwork, leading to the conclusion that darker pigmented angles do better with SLT. 
TABLE 5: The role of gender in the outcome of selective laser trabeculoplasty.

\begin{tabular}{|c|c|c|c|c|}
\hline Gender $(p<0.001)$ & Time & Mean IOP $(\mathrm{mmHg})$ & Mean IOP reduction & Reduction from baseline (\%) \\
\hline \multirow[t]{5}{*}{ Female } & Pre SLT & 20.59 & - & - \\
\hline & $1 / 12$ post SLT & 15.07 & -12.00 & 44.3 \\
\hline & $3 / 12$ post SLT & 14.20 & -12.87 & 47.6 \\
\hline & $6 / 12$ post SLT & 14.41 & -12.66 & 46.8 \\
\hline & $12 / 12$ post SLT & 12.58 & -14.49 & 53.5 \\
\hline \multirow[t]{4}{*}{ Male } & Pre SLT & 20.51 & - & - \\
\hline & $3 / 12$ post SLT & 15.66 & -3.31 & 17.4 \\
\hline & $6 / 12$ post SLT & 14.70 & -4.26 & 22.5 \\
\hline & $12 / 12$ post SLT & 13.35 & -5.62 & 29.6 \\
\hline
\end{tabular}

IOP, intraocular pressure; SLT, selective laser trabeculoplasty.

TABLE 6: The role of ethnicity in the outcome of selective laser trabeculoplasty.

\begin{tabular}{|c|c|c|c|c|}
\hline Ethnicity $(p<0.001)$ & Time & Mean IOP (mmHg) & Mean IOP reduction & Reduction from baseline (\%) \\
\hline \multirow[t]{5}{*}{ African } & Pre SLT & 21.64 & - & - \\
\hline & $1 / 12$ post SLT & 14.67 & -12.40 & 45.8 \\
\hline & $3 / 12$ post SLT & 15.04 & -12.02 & 44.4 \\
\hline & $6 / 12$ post SLT & 14.70 & -12.37 & 45.7 \\
\hline & $12 / 12$ post SLT & 12.93 & -14.14 & 52.2 \\
\hline \multirow[t]{5}{*}{ Indian } & Pre SLT & 18.35 & - & - \\
\hline & $1 / 12$ post SLT & 14.41 & -4.56 & 24.0 \\
\hline & $3 / 12$ post SLT & 14.09 & -4.87 & 25.7 \\
\hline & $6 / 12$ post SLT & 14.37 & -4.60 & 24.3 \\
\hline & $12 / 12$ post SLT & 13.32 & -5.64 & 29.8 \\
\hline
\end{tabular}

IOP, intraocular pressure; SLT, selective laser trabeculoplasty.

At 1 year, African patients showed a reduction in their mean IOP of $52 \%$ from baseline compared with a reduction of $30 \%$ in the Indian group. The small number of Caucasian patients enrolled in the trial precluded their inclusion in this comparison (see Table 6).

Evaluating for age, we found that patients from the 50-year age group had a reduction in their IOP of $37 \%$ at 1 year, those in the 60 -year group had a reduction of $39 \%$ and those in the 70 -year group had a reduction of $57 \%$.

Prior to the trial, 36 eyes of 26 patients had undergone surgical intervention for glaucoma. These included 28 trabeculectomies, 3 Ahmed glaucoma valves, 22 phaco-emulsifications and 1 ALT.

By the conclusion of the study, no patient from Group A had required any surgery. In contrast, three of the Group B patients had undergone further glaucoma surgeries including one trabeculectomy and one phaco-emulsification combined with an Express valve implant.

The eyes that underwent surgery prior to or during the trial had a reduction in mean IOP of more than $20 \%$ at 1 year in $81 \%$ of cases. Interestingly, the same percentage of cases $(81 \%)$ of those patients never having had any surgery $(n=58)$ also had a reduction in mean IOP of greater than $20 \%$ at 1 year. The surgical group had an IOP reduction of 33\% at 1 year, despite the advanced nature of their disease and having had multiple treatments in the past.

There was no statistically significant risk of SLT failure in the surgical group compared with the non-surgical group.
The surgical group had a reduction in their mean IOP of $4.05 \mathrm{mmHg}(22 \%)$ at 1 month, $5.5 \mathrm{mmHg}(30 \%)$ at 3 months, $4.3 \mathrm{mmHg}(23 \%)$ at 6 months and $6.1 \mathrm{mmHg}(33 \%)$ at 1 year. These levels were on par with the non-surgical groups and exceeded the $20 \%$ drop proposed by the EGS ${ }^{1}$ and the American Academy of Ophthalmology. ${ }^{7}$

\section{Discussion}

In this study, the best outcomes were seen in older and darker pigmented patients. These comprise the majority of patients treated in our hospital. Ninety percent of African patients had a reduction in IOP of greater that $20 \%$, similar to the findings by Seck et al. who also showed efficiency in $90 \%$ of African black patients in their study. ${ }^{11}$

SLT only affects pigmented trabecular meshwork cells, explaining the greater effect in pigmented races. In vitro investigation showed that non-pigmented cells did not experience collateral thermal damage. ${ }^{12}$

SLT laser energy recruits macrophages to the trabecular meshwork by increasing the expression of cytokines and cellular mediator activities. Macrophages remove obstructive proteins and remodel the trabecular meshwork, thus improving aqueous outflow and reducing the IOP. ${ }^{8}$

It is also noted that these biological changes may take up to 6 weeks to take effect. ${ }^{13}$ Retreatment before this period is not recommended. It is advised to monitor these patients closely initially until the laser has taken effect. In patients with extremely high IOP, it may be prudent to cover them with medical therapy for the first 6 weeks, followed by a tapering period. 
In this study, only patients with a minimum of 1-year followup were included. It is not possible to discuss the duration of effect on these patients. Weinand et al. looked at the survivability of SLT and found that around 50\% of patients had treatment failure at 2 years, ${ }^{5}$ and this finding was reproduced by Bovell et al. ${ }^{6}$

Group A patients required significantly less topical and systemic IOP-lowering medications and had the added benefit of not needing surgical intervention during the study period. Two patients belonging to Group B became pregnant during the trial allowing them to be taken off potentially teratogenic medications.

SLT has a great advantage compared with medical therapy, as it does not rely on compliance. Electronic eye drop monitoring revealed $76 \%-86 \%$ drop in compliance, and evaluation of prescription claims showed patients had glaucoma drops available to use $69 \%$ of the time. ${ }^{14}$ This is worrying when dealing with blinding conditions. Taking the compliance out of the equation improves the success rate over time. Reducing the amount of medications and trips to the pharmacy will also improve the quality of life for all these patients. The financial implications connected to the reduced need for medication is important to the patient as well as the government hospitals.

However, it was difficult to wean the Group B patients off their chronic medications, but acetazolamide use decreased by $15 \%$, improving the quality of life of some of the patients. Patients on acetazolamide often complain of debilitating muscle cramps and tingling of extremities and the lips. It is probably the drug that is discontinued first by these patients, a fact that is seldom conveyed to the treating clinician. Seck et al. demonstrated a discontinuation of prostaglandin drops in $60 \%$ of study patients. ${ }^{11}$ Our study showed no drop in the use of prostaglandins, with $89 \%$ of Group B on chronic prostaglandin drops.

It was a surprise to see the disparity between genders. The percentage of patients who had a reduction in IOP of more than $20 \%$ were similar in both groups, with $82 \%$ of male patients and $77 \%$ of female patients reaching the target. The female group had a $54 \%$ reduction in IOP from baseline compared with $30 \%$ in the male group. This was not the case in other international studies, where no significant difference was found. . $^{15,16,17}$

SLT preserves the conjunctiva, should future surgical intervention be needed. It can safely be repeated numerous times and is relatively easy to perform with minimal patient discomfort and minimal side effects. The effect of future drainage surgery is greatly influenced once the conjunctiva has been damaged by other surgical intervention.

Most ophthalmology units have access to argon laser. ALT was found to be as effective as SLT in reducing the IOP, but the laser energy caused permanent tissue damage in the trabecular meshwork and cannot be repeated. ${ }^{18}$ SLT has a much better side effect profile and is repeatable as seen by Hong et al. ${ }^{19}$ Subsequent treatments are effective even if the initial treatment was not.

Unfortunately, most studies excluded patients with prior glaucoma surgery. In our study, we did show a significant reduction of IOP in patients who had prior trabeculectomies, glaucoma drainage valves, cataract surgery and glaucoma shunts. Only 3 of the 37 eyes in the prior surgical group required further glaucoma surgery. Of note is that none of the patients in Group A required any surgical intervention to lower IOP over the 1-year follow-up.

A mean reduction in IOP of 35\% was achieved at 1-year after SLT. It was also found that $80 \%$ of these patients had a drop in IOP of greater than $20 \%$.

There is enough evidence to advocate the addition of an SLT unit to all government eye centres as it markedly reduces the need for medication, with its accompanying side effects and compliance issues, as well as the need for surgical intervention, with well-known failure rates and morbidity. It is also technically easier to perform than glaucoma surgery. Even the most junior medical officer or resident can perform the procedure without difficulty. There is no steep learning curve to overcome, as it utilises the slit lamp and a gonioscopy lens, both of which are familiar to the ophthalmologist in training.

This is of particular importance in units with staff shortages, a common theme in most government institutions. The procedure can be completed within a few minutes, making 'same-day treatment' a reality, reducing clinic numbers and patient waiting times.

There are known complications of SLT therapy. The EGS guidelines list anterior chamber inflammation, iritis, anterior chamber bleed, IOP spikes and the formation of peripheral anterior synechiae as possible complications. ${ }^{1}$ None of the eyes treated during the trial were noted to have any of the side effects mentioned. Compared with the numerous and sometimes unmanageable side effects of topical and systemic IOP-lowering agents and complications of surgical intervention, SLT seems a much simpler and safer choice. Unfortunately, this study was conducted as a retrospective review, meaning some of the side effects may have been missed.

This study did show that SLT as a first line was a viable option, as seen by Waisbourn. ${ }^{20}$ Combined with the reduced need for medication, it is advocated in the treatment of POAG.

This study only included 148 eyes of 84 patients. This is a relatively small sample, but still comparable with international studies. Weinand et al. had a sample size of 52 patients $^{5}$ and Seck et al. studied 40 patients. ${ }^{11}$ A larger study sample would have been ideal. It would also have been better to have groups 
of equal size regarding ethnicity to evaluate the contribution of ethnicity to the eventual efficiency of the SLT laser.

Being a retrospective study, the procedure was not standardised. IOP was not measured at the same time of day by the same examiner using the same tonometer. The exact number of laser burns was not always noted in the patient's chart. Certain doctors preferred to do 180 degrees of laser, while others preferred 360 degrees. Follow-up of all patients can be difficult in the state sector, as attendance can be affected by finances, protest action affecting patient transport and other medical comorbidities that may take preference over eye clinic follow-ups.

The study was done as a retrospective chart review. A prospective randomised controlled trial is advocated in the future to confirm the results.

The ideal test of SLT compared with medical treatment is not easily done. This would entail treating one eye medically and one eye with SLT. The medications instilled or used systemically to control IOP in the 'medical eye' would be absorbed systemically and lower the IOP in the 'SLT eye' as well, leading to exaggerated results, as seen by Lai et al. ${ }^{21}$ and Best et al. ${ }^{22}$ The only way around this is to treat both eyes medically, measure the IOP and then follow with a 'washout period' where all treatment is stopped. The exact duration varies between medications used. SLT and further monitoring of the IOP could then follow this. Patients are thus without treatment for a period of time.

\section{Conclusion}

In evaluating the efficacy, ease of application and favourable risk profile, it is highly recommended that SLT be made commonplace in the treatment of POAG, especially in those patients who present for the first time.

\section{Acknowledgements Competing interests}

The authors declare that they have no financial or personal relationships which may have inappropriately influenced them in writing this article.

\section{Authors' contributions}

E.G. was the project leader. E.G. and L.V. were responsible for the experimental and project design. Calculations were performed by B.S.

\section{References}

1. Blanco AA, et al. European Glaucoma Society. Terminology and guidelines for glaucoma. 3rd ed. 2008. [cited n.d.]. Available from http://www.eugs.org

2. El Sayyad F, Helal M. Update on laser trabeculoplasty. Middle East Afr Ophthalmol. 2009;16(3):116-118. http://dx.doi.org/10.4103/0974-9233.56221

3. Katz L, Steinmann W, Kabir A, Molineaux J, Wizov S, Marcellino G. Selective laser trabeculoplasty versus medical therapy as initial treatment of glaucoma: A prospective, randomized trial. J Glaucoma. 2012;21(7):460-468.

4. Kara N, Altan C, Satana B, et al. Comparison of laser trabeculoplasty success in patients treated with either prostaglandin or timolol/dorzolamide fixed combination. J Ocul Pharmacol Ther. 2011;27(4):339-342. http://dx.doi. org/10.1089/jop.2011.0015

5. Weinand F, Althen F. Long-term clinical results of selective laser trabeculoplasty in the treatment of primary open angle glaucoma. Eur J Ophthalmol. 2006;16(1):100-104.

6. Bovell AM, Damji KF, Hodge WG, Rock WJ, Buhrmann RR, Pan YI. Long term effect on the lowering of intraocular pressure: Selective laser or argon lase trabeculoplasty? Can J Ophthalmol. 2011;46(5):408-413. http://dx.doi.org/ 10.1016/j.jcjo.2011.07.016

7. Prum BE, Lim MC, Mansberger SL, et al. American Academy of Ophthalmology. Preferred practice pattern, Primary open angle glaucoma suspect. 2015.

8. Shazly T, Latina M, Dagianis J, Chitturi S. Effect of prior cataract surgery on the long-term outcome of selective laser trabeculoplasty. Clin Ophthalmol. 2011;5:377-380. http://dx.doi.org/10.2147/OPTH.S17237

9. The Glaucoma Laser Trial Research Group. Am J Ophthalmol. 1995;20(6): 718-731.

10. Samples JR. Laser trabeculoplasy for open-angle glaucoma: A report by the American Academy of Ophthalmology. Ophthalmology. 2011;118(11):2296-2302. http://dx.doi.org/10.1016/j.ophtha.2011.04.037

11. Seck SM, Agboton G, Dieng M, et al. Selective laser trabeculoplasty (SLT): Our experience in African blacks. J Fr Ophthalmol. 2015;38(3):238-246. http://dx.doi. org/10.1016/j.jfo.2014.11.002

12. Latina MA, Park C. Selective targeting of trabecular meshwork cells: In vitro studies of pulsed and CW laser interactions. Exp Eye Res. 1995;60(4):359-371. http://dx.doi.org/10.1016/S0014-4835(05)80093-4

13. Stein JD, Challa P. Mechanisms of action and efficacy of argon laser trabeculoplasty and selective laser trabeculoplasty. Curr Opin Ophthalmol. 2007;18(2):140-145. http://dx.doi.org/10.1097/ICU.0b013e328086aebf

14. Schwartz GF, Quigley HA. Adherence and persistence with glaucoma therapy. Surv Ophthalmol. 2008;53(Suppl 1):S57-S68. http://dx.doi.org/10.1016/j.survophthal. 2008.08.002

15. Rhodes KM, Weinstein R, Saltzmann RM, et al. Intraocular pressure reduction in the untreated fellow eye after selective laser trabeculoplasty. Curr Med Res Opin 2009;25(3):787-796. http://dx.doi.org/10.1185/03007990902728316

16. Kano K, Kuwayama $\mathrm{Y}$, Mizoue S, Ito $\mathrm{N}$. Clinical results of selective laser trabeculoplasty. Nippon Ganka Gakkai Zasshi. 199;103(8):612-616.

17. Kontić M, Ristić D, Vukosavljević M. Hypotensive effect of selective laser trabeculoplasty in patients with medically uncontrolled primary open-angle glaucoma. Srp Arh Celok Lek. 2014;142(9-10):524-528. http://dx.doi.org/ 10.2298/SARH1410524K

18. McAlinden C. Selective laser trabeculoplasty (SLT) vs other treatment modalities for glaucoma: Systematic review. Eye. 2014;28:249-258. http://dx.doi.org/ 10.1038/eye.2013.267

19. Hong B, Winer JC, Martone JF, Wand M, Altman B, Shields B. Repeat selective laser trabeculoplasty. J Glaucoma. 2009;18(3):180-183. http://dx.doi.org/10.1097/ IJG.0b013e31817eee0b

20. Waisbourn M, Katz LJ. Selective laser trabeculoplasty as first-line therapy: A review. Can J Ophthalmol. 2014;49(6):519-522. http://dx.doi.org/10.1016/j. jcjo.2014.10.003

21. Lai JS, Chua JK, Tham CC, Lam DS. Five-year follow up of selective laser trabeculoplasty in Chinese eyes. Clin Experiment Ophthalmol. 2004;32:368-372. http://dx.doi.org/10.1111/j.1442-9071.2004.00839.x

22. Best UP, Domack H, Schmidt V. Pressure reduction after selective laser trabeculoplasty with two different laser systems and after argon lase trabeculoplasty - A controlled prospective clinical trial on 284 eyes. Klin Monb Augenheilkd. 2007;224:173-179. http://dx.doi.org/10.1055/s-2007-963014 